\title{
Synthesis and fluorescence of a series of multichromophoric acenaphthenyl compounds
}

Ming Chen, ${ }^{\dagger}$ Kenneth P. Ghiggino, ${ }^{* \dagger}$ Jonathan White, ${ }^{\dagger}$ San H. Thang, ${ }^{*}$ and Gerard J. Wilson ${ }^{*}$

${ }^{\dagger}$ School of Chemistry, The University of Melbourne, Victoria 3010, Australia

${ }^{\ddagger}$ CSIRO Molecular Science, Bag 10, Clayton South, Victoria 3169, Australia

ghiggino@unimelb.edu.au

Table of Contents

General Experimental Methods

S-2

References

S-4

${ }^{1} \mathrm{H}$ NMR spectrum of $\mathbf{2}$

S-5

${ }^{13} \mathrm{C}$ NMR spectrum of 2

S-6

${ }^{1} \mathrm{H}$ NMR spectrum of $\mathbf{3}$

${ }^{13} \mathrm{C}$ NMR spectrum of $\mathbf{3}$

S-8

${ }^{1} \mathrm{H}$ NMR spectrum of 4

${ }^{13} \mathrm{C}$ NMR spectrum of 4

${ }^{1} \mathrm{H}$ NMR spectrum of 5

${ }^{13} \mathrm{C}$ NMR spectrum of 5

${ }^{1} \mathrm{H}$ NMR spectrum of $\mathbf{6}$

${ }^{13} \mathrm{C}$ NMR spectrum of 6

S-14 
${ }^{1} \mathrm{H}$ NMR spectrum of 7

${ }^{13}$ C NMR spectrum of $7 \quad$ S-16

$\begin{array}{ll}{ }^{1} \mathrm{H} \text { NMR spectrum of } \mathbf{8} & \text { S-17 }\end{array}$

${ }^{13}$ C NMR spectrum of $8 \quad$ S-18

$\begin{array}{lr}{ }^{1} \mathrm{H} \text { NMR spectrum of } 9 & \text { S-19 }\end{array}$

${ }^{13}$ C NMR spectrum of $9 \quad$ S-20

${ }^{1} \mathrm{H}$ NMR spectrum of $\mathbf{1 0} \quad$ S-21

${ }^{13} \mathrm{C}$ NMR spectrum of $\mathbf{1 0} \quad$ S-22

${ }^{1} \mathrm{H}$ NMR spectrum of $\mathbf{1 1} \quad$ S-23

${ }^{13}$ C NMR spectrum of $\mathbf{1 1} \quad$ S-24

\section{General Experimental Methods:}

Acenaphthylene and 2,2'-azobis(isobutyronitrile) (AIBN) were recrystallized from methanol. 2Cyanopropan-2-yl dithiobenzoate (1) was synthesized as reported. ${ }^{1}$ All other starting materials were used as received. Solvents used for absorption and fluorescence measurements were spectroscopic grade and were checked for fluorescent impurities prior to use. When deaerated conditions were required, solutions were degassed by multiple freeze-pump-thaw cycles to $\sim 10^{-6}$ torr in $1 \mathrm{~cm}$ square quartz cells with attached bulbs and grease-free taps.

Analytical thin-layer chromatography (TLC) was performed using glass plates pre-coated with silica gel (0.25 mm, $60 \AA$ pore size, 230-400 mesh) impregnated with a fluorescent indicator (254 nm). TLC plates were visualized by exposure to ultraviolet light (UV) at 254 and $365 \mathrm{~nm}$.

UV-Vis absorption spectra were recorded against solvent blanks in matched $1.0 \mathrm{~cm}$ path-length quartz cells. The optical density of the solutions for fluorescence measurements was kept below 0.10 at the 
excitation wavelength. Fluorescence and excitation spectra were corrected for the wavelength dependence of detector sensitivity and excitation light source output.

Analytical reverse phase HPLC was performed using a $150 \times 4.6 \mathrm{~mm} \mathrm{C18} \mu \mathrm{m}$ column and a photodiode array detector monitoring at 200-600 $\mathrm{nm}$.

Preparative reverse phase HPLC was performed using a $250 \times 22 \mathrm{~mm}$ C18 $5 \mu \mathrm{m}$ column, an injector with $2 \mathrm{~mL}$ sample loop and a spectrophotometer monitoring at $290 \mathrm{~nm}$. The sample loading amount was about $100 \mathrm{mg}$.

${ }^{1} \mathrm{H}$ and ${ }^{13} \mathrm{C}$ NMR spectra were recorded on either a spectrometer with ${ }^{1} \mathrm{H} 500.13 \mathrm{MHz}$ and ${ }^{13} \mathrm{C} 126.77$ $\mathrm{MHz}$ or a spectrometer with ${ }^{1} \mathrm{H} 400.13 \mathrm{MHz}$ and ${ }^{13} \mathrm{C} 100.63 \mathrm{MHz}$ at $25{ }^{\circ} \mathrm{C}$ in deuterated solvents as stated. Proton chemical shifts are expressed in parts per million (ppm, $\delta$ scale) downfield from tetramethylsilane and are referenced to residual protonated NMR solvent signal. Carbon chemical shifts are expressed in parts per million (ppm, $\delta$ scale) downfield from tetramethylsilane and are referenced to the carbon resonance of the NMR solvent Spectra. Multiplicities of ${ }^{1} \mathrm{H}$ NMR are reported as singlet (s), doublet (d), triplet (t), or quartet (q), with combinations as necessary (such as dd), or multiplet (m), prefixed as broad (b) where appropriate. Homonuclear coupling constants $(J)$ are reported in Hertz $(\mathrm{Hz})$. Assignments were based on homonuclear two-dimensional COSY and NOESY experiments, and heteronuclear two-dimensional HSQC and HMBC experiments.

Positive ion Electron Impact (EI) mass spectra were run on a mass spectrometer using an ionisation energy of $70 \mathrm{eV}$. Accurate mass measurements were obtained with a resolution of 5000-10000 using PFK as the reference compound.

X-ray Crystallography. Intensity data for 7 were collected on an diffractometer using nickel-filtered $\mathrm{Cu}-\mathrm{K} \alpha$ radiation (graphite crystal monochromator $=1.54186 \AA$ ) and processed using the program Process_data. ${ }^{2}$ The crystals of 7 contained two molecules of the dimer and one $\mathrm{CH}_{2} \mathrm{Cl}_{2}$ in one asymmetric unit. However, the $\mathrm{CH}_{2} \mathrm{Cl}_{2}$ was disordered and very difficult to model satisfactorily. The 
contribution of the electron density associated with the $\mathrm{CH}_{2} \mathrm{Cl}_{2}$ was removed using the SQUEEZE procedure with the program PLATON. ${ }^{3}$ The total avoid volume was $297 \AA^{3}$ with a positive electron count of 86 consistent with the presence of two molecules of $\mathrm{CH}_{2} \mathrm{Cl}_{2}$ in the unit cell. Intensity data for all the other compounds were collected with a CCD detector using Mo-K $\alpha$ radiation (graphite crystal monochromator $=0.71073 \AA$ ). Data were reduced using the program $S A I N T{ }^{3}$ The structures were solved by direct methods and difference Fourier techniques. Hydrogen atoms were included in calculated positions. Full-matrix least-squares refinement on $F^{2}$, using all data, was carried out with anisotropic displacement parameters applied to all non-hydrogen atoms.

\section{References:}

1. Thang, S. H.; Chong, Y. K.; Mayadunne, R. T. A.; Moad, G.; Rizzardo, E.; Tetrahedron Lett. 1999, 40, 2435.

2. Gable, R. W.; Hoskins, B. F.; Linden, A.; McDonald, I. A. S.; Steen, R. J. PROCESS_DATA. A Program for the Processing of CAD-4 Diffractometer Data, The University of Melbourne, Australia, 1993.

3. Spek, A. L. PLATON for windows. A Program for Absorption Corrections, University of Utrecht, The Netherlands, 1999. 

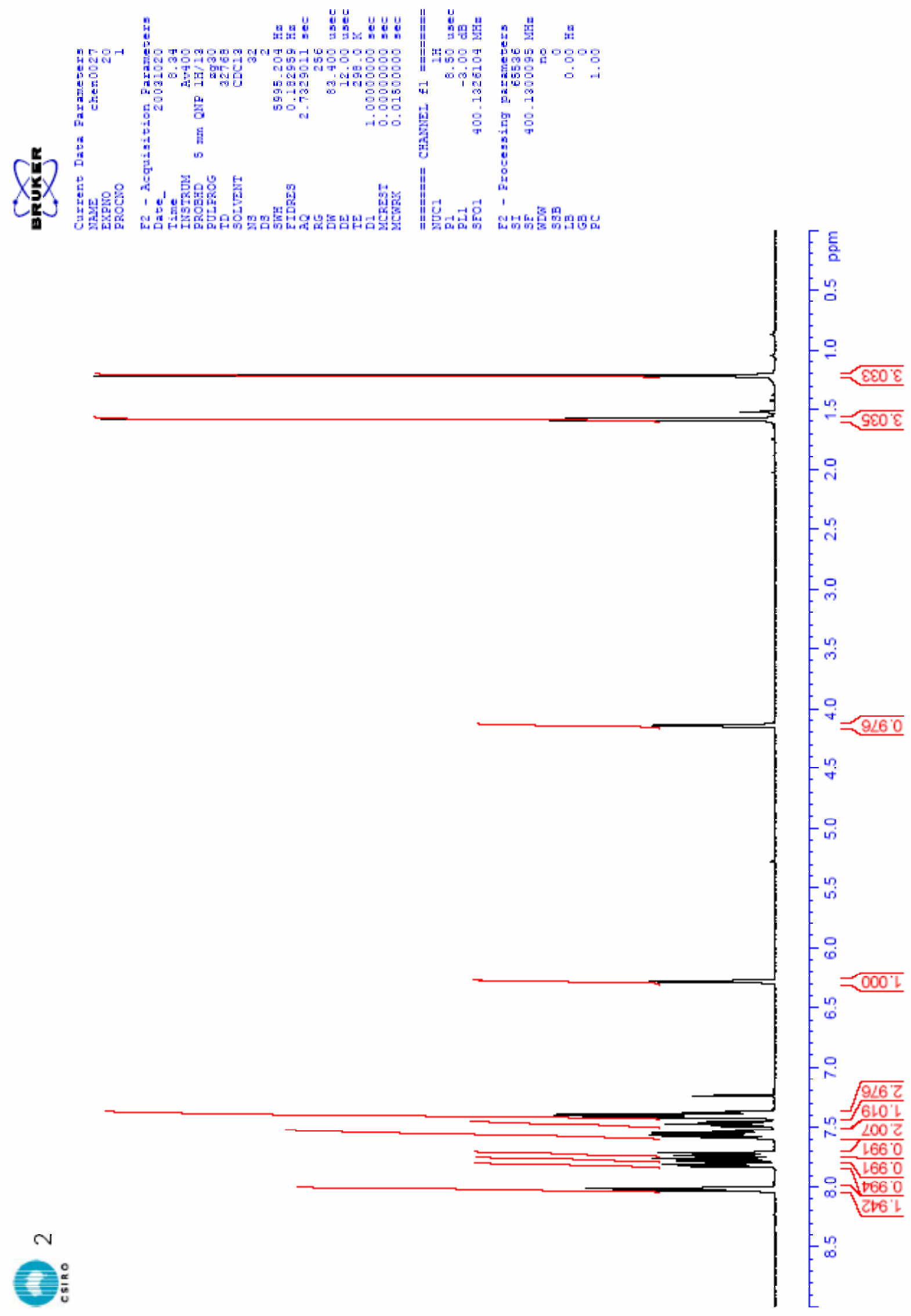

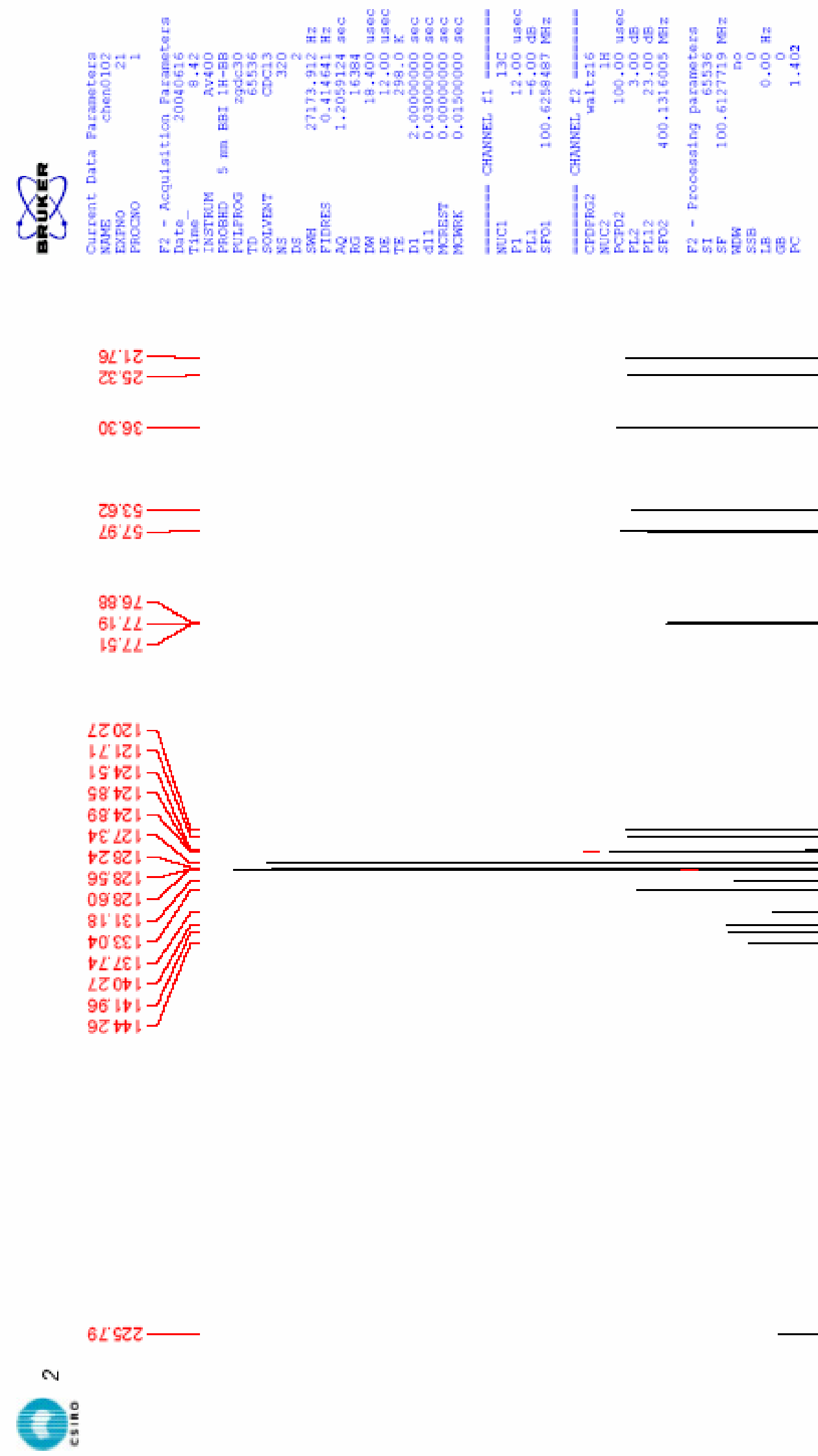

$6 I \mathrm{SZZ}$
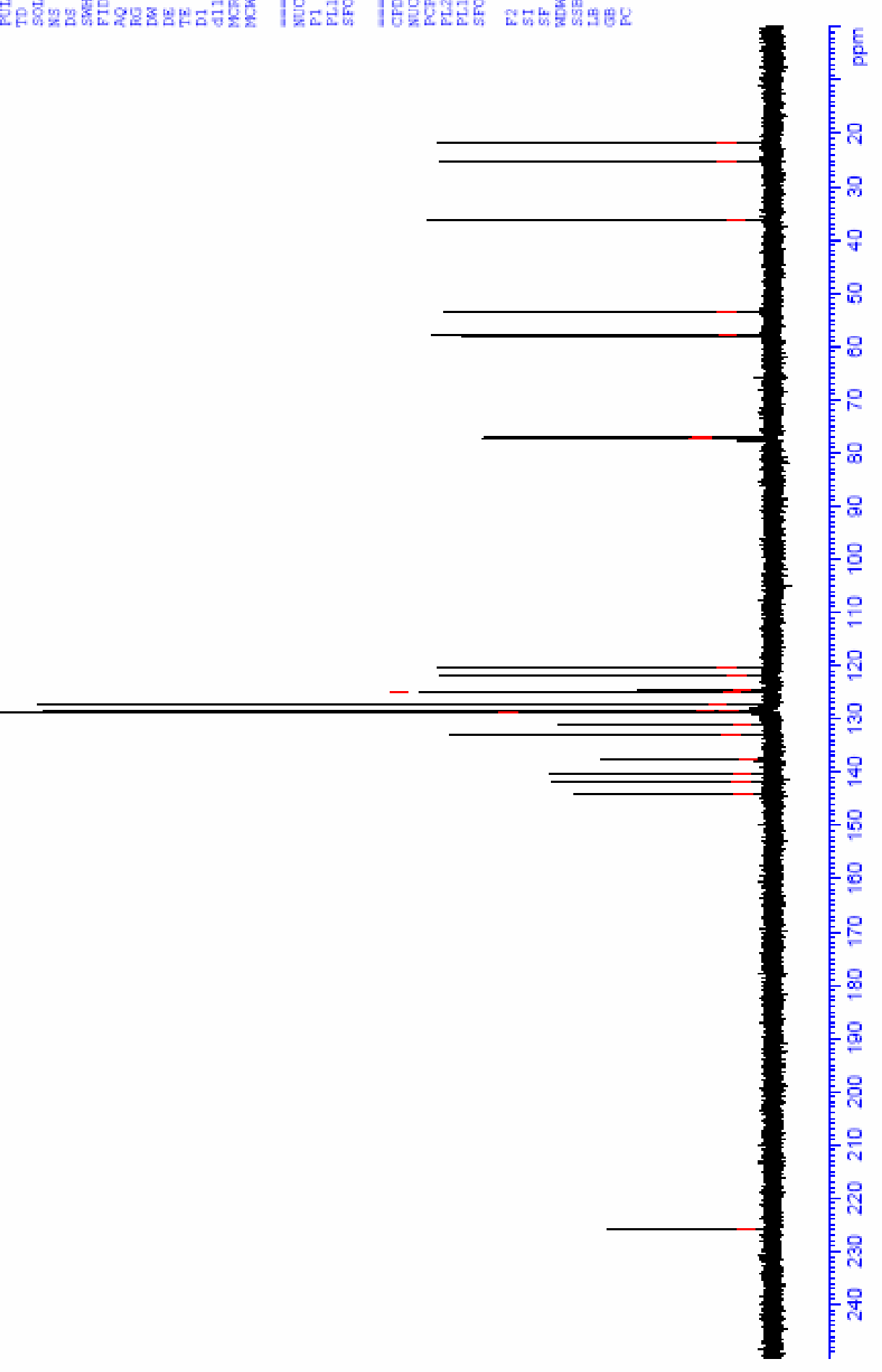

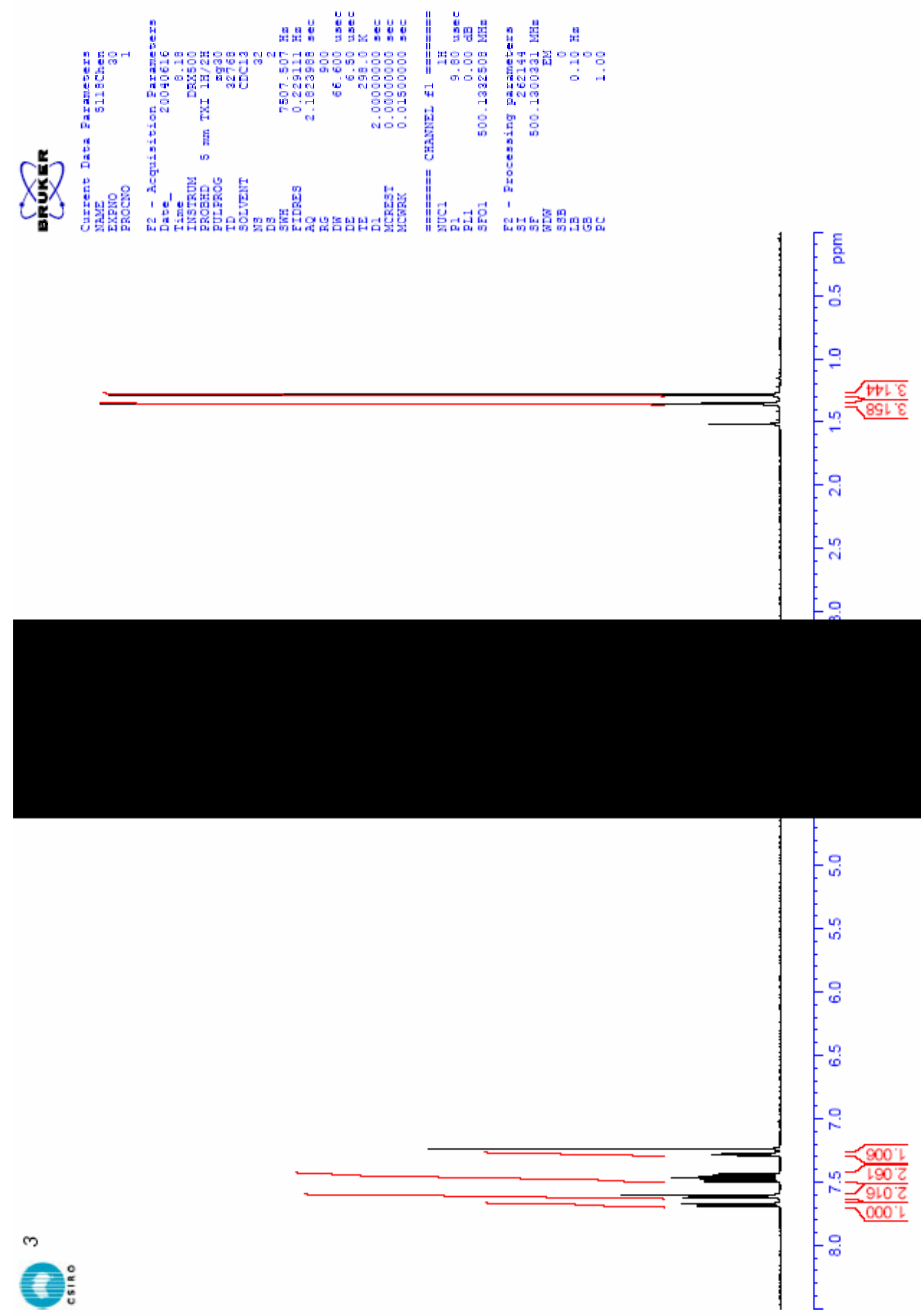


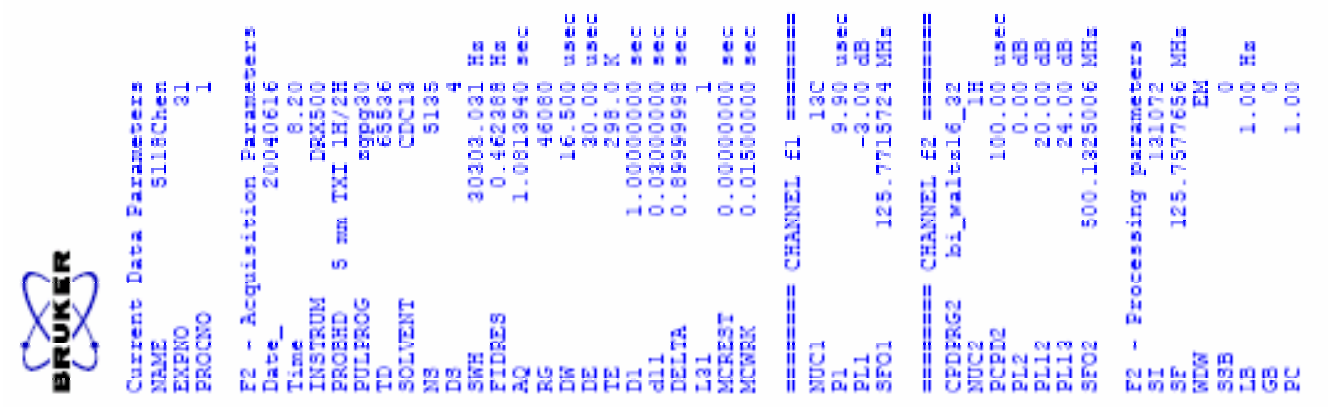

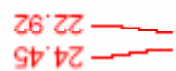

$\forall V^{\circ}=$

$08^{\prime} 09$

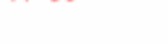

86 ' 94 $8 \mathrm{C}^{\circ} \angle L$

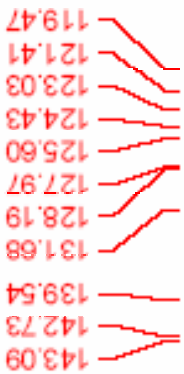

$m$
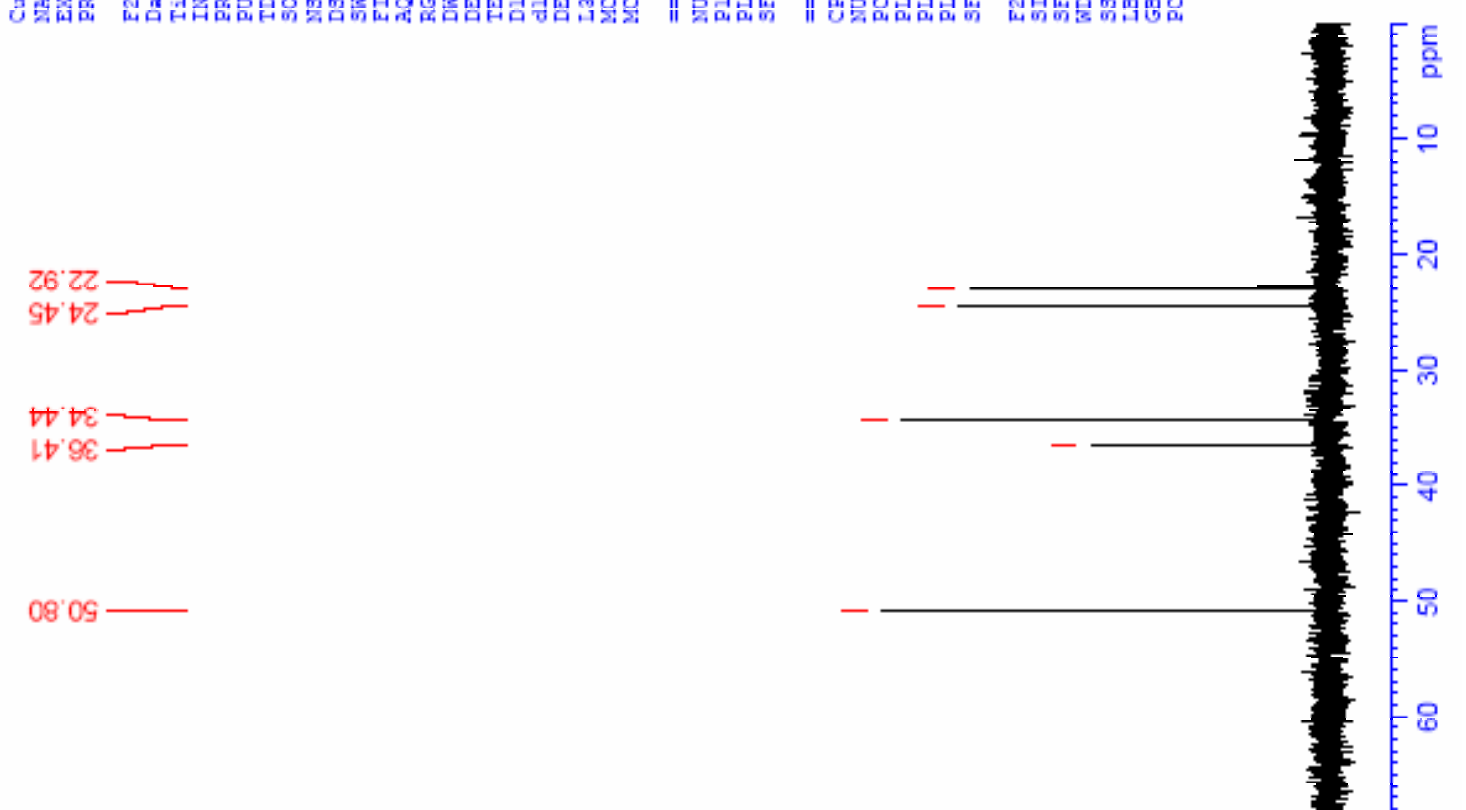


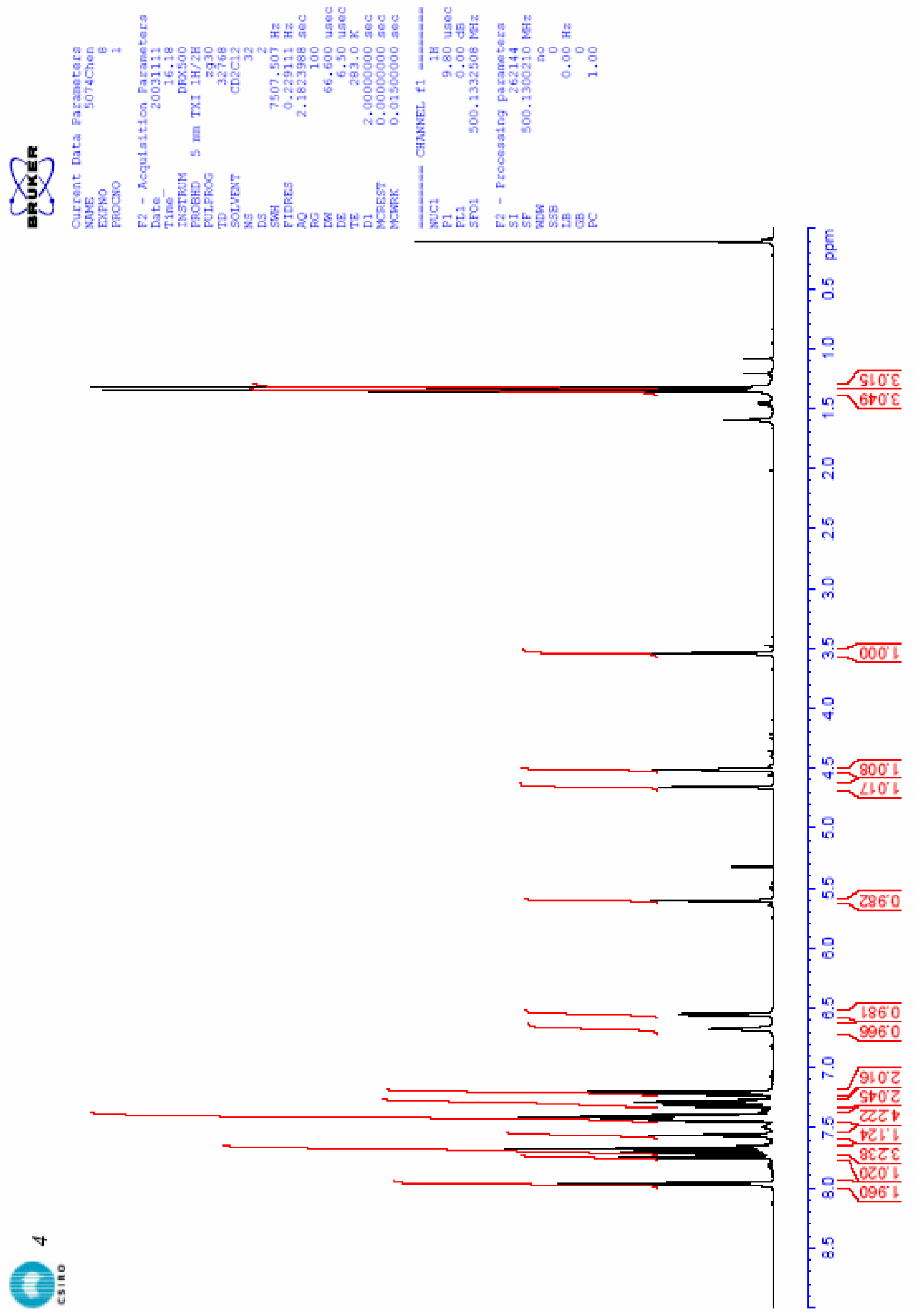



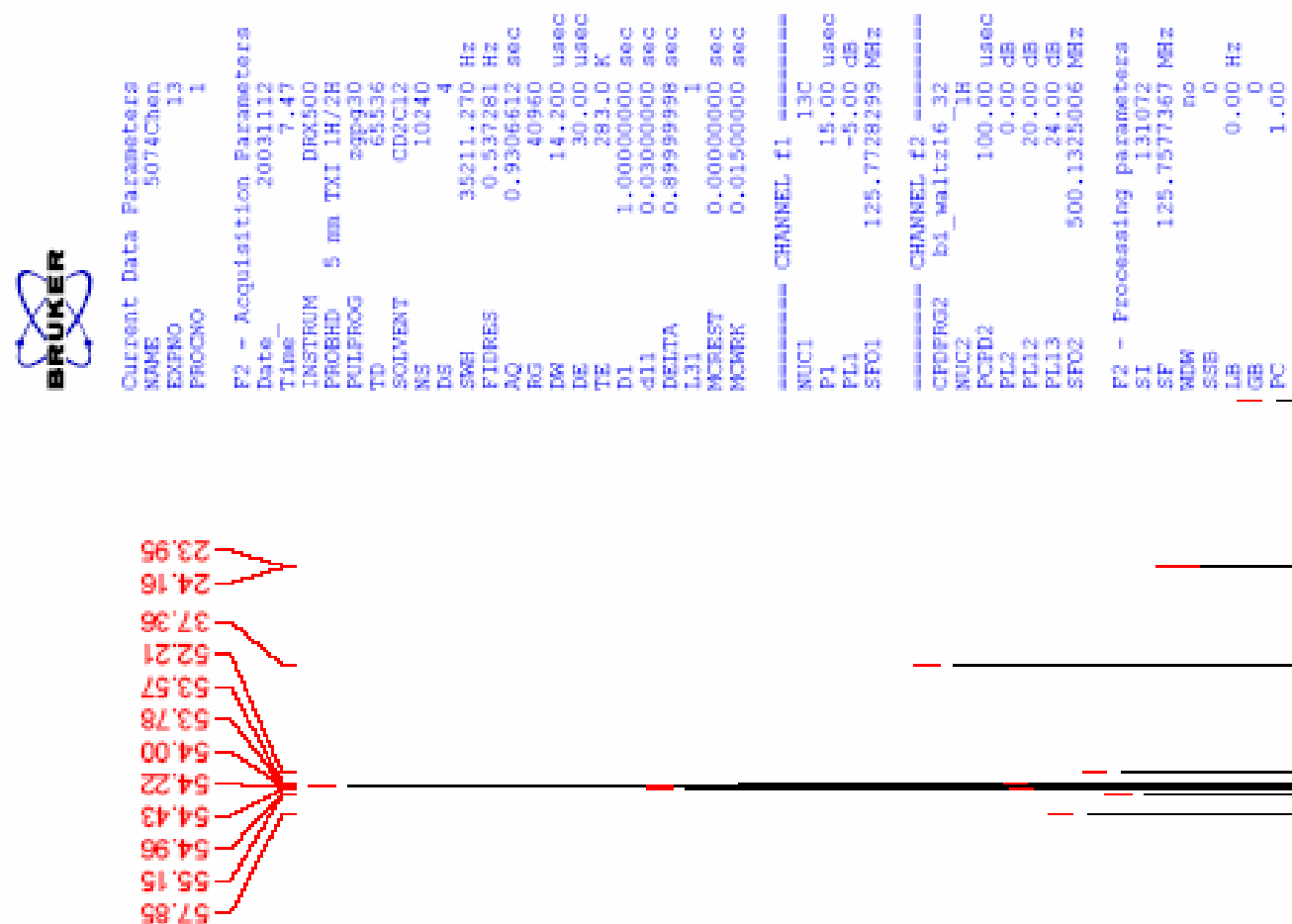

9829

$6 Z \mathrm{OZ}$ !

$690 \mathrm{C} !$

$9 \angle 021$

$0 Z Z \square-7$

$z z \mathrm{bz}$

$\overline{8} \bar{c} \nabla \bar{c} \downarrow$

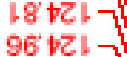

LG $\subseteq$ ।

$6 \mathrm{E} Z Z$

$0 \forall \angle Z$

$80 \mathrm{gc}$

9f'gz.

oc $9 \mathrm{C}$

cagi

$999 \mathrm{~L}$

टहा है।

ZSIE!

cl'est

0695

citot b

cyzbl

1.

isct-

$98+1-$

$9 \bar{c} \operatorname{lcz} \longrightarrow$

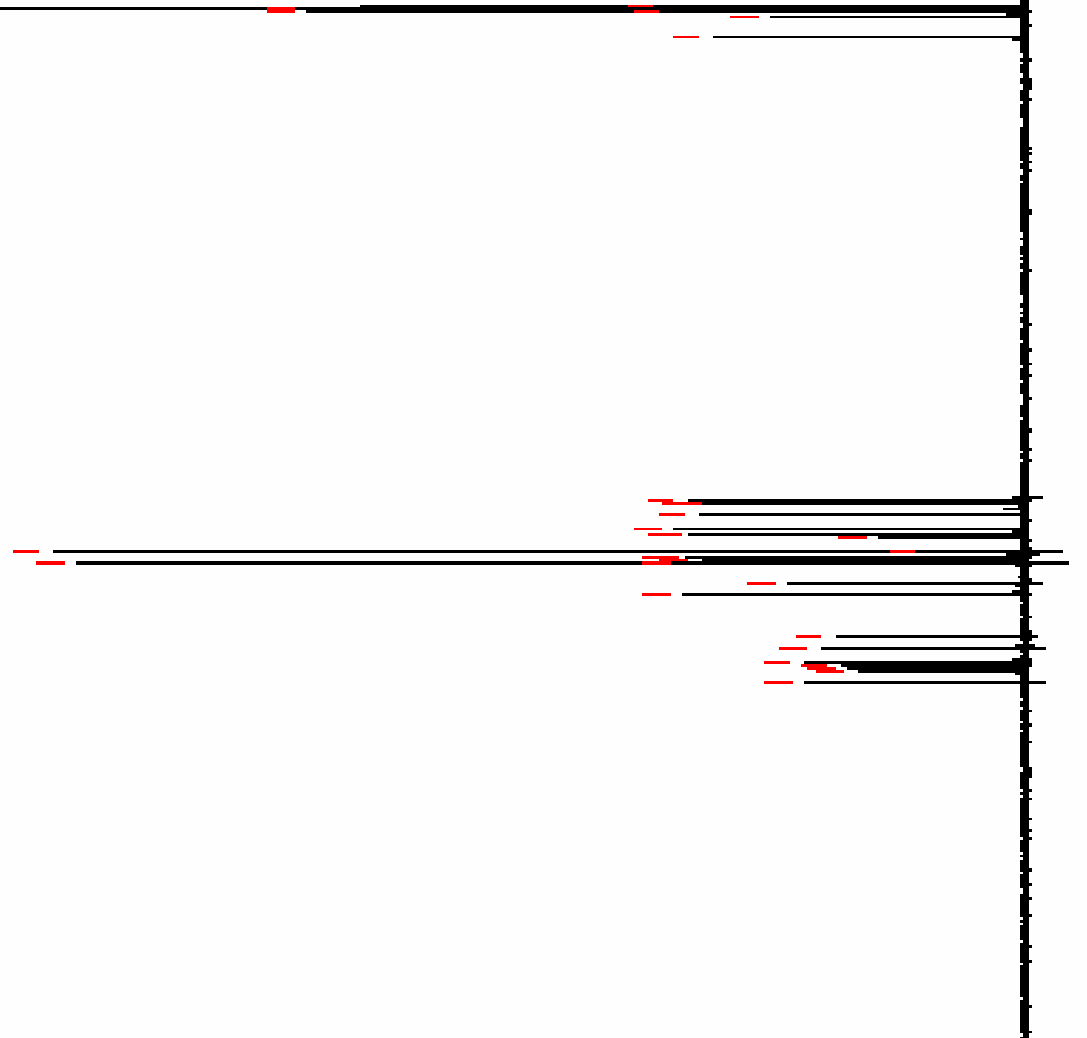

的

용

옹

응

흠

을

웜

뭉

是昌

=

要

응

,

을

음

잉

음

음

은

을

동 

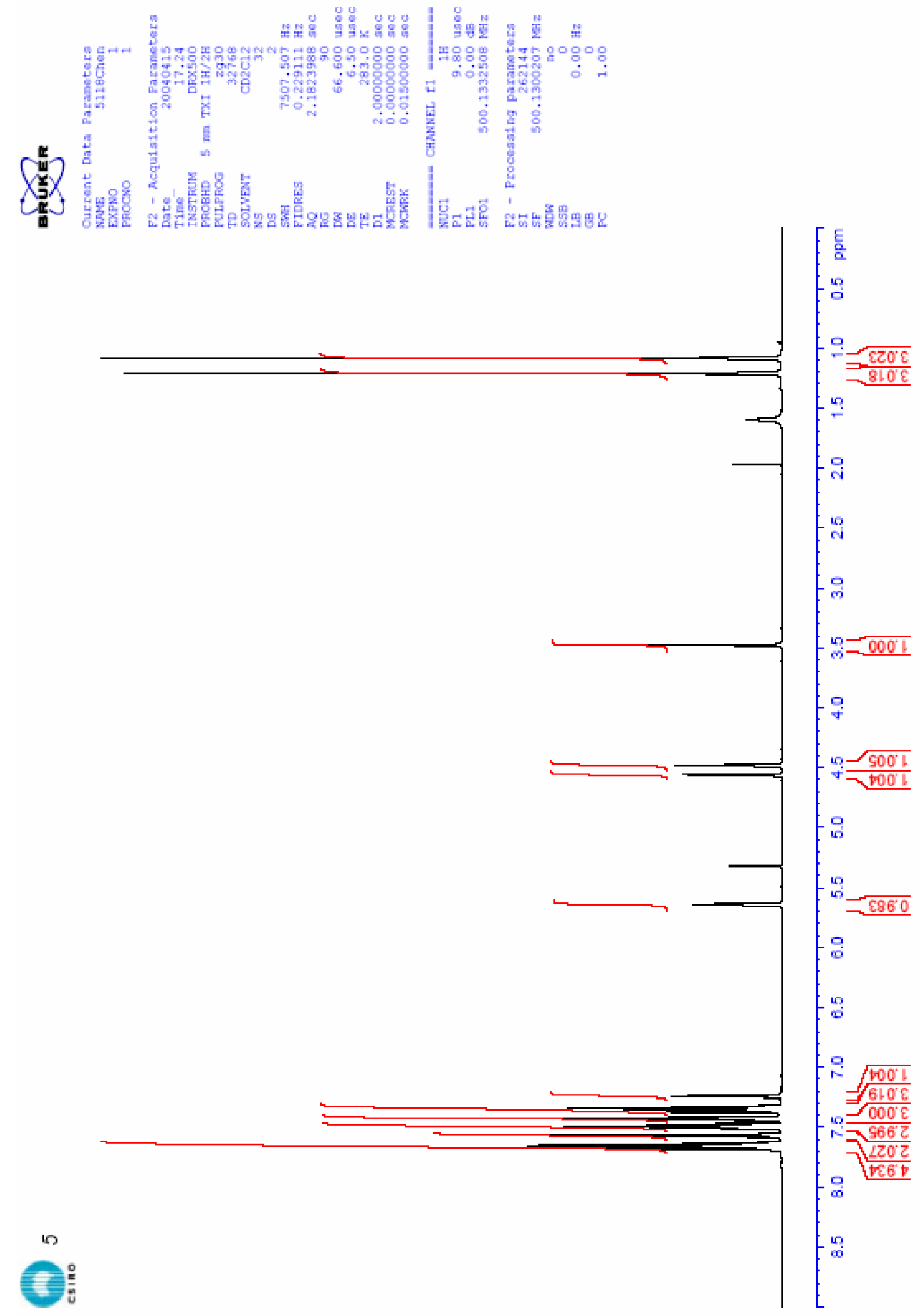


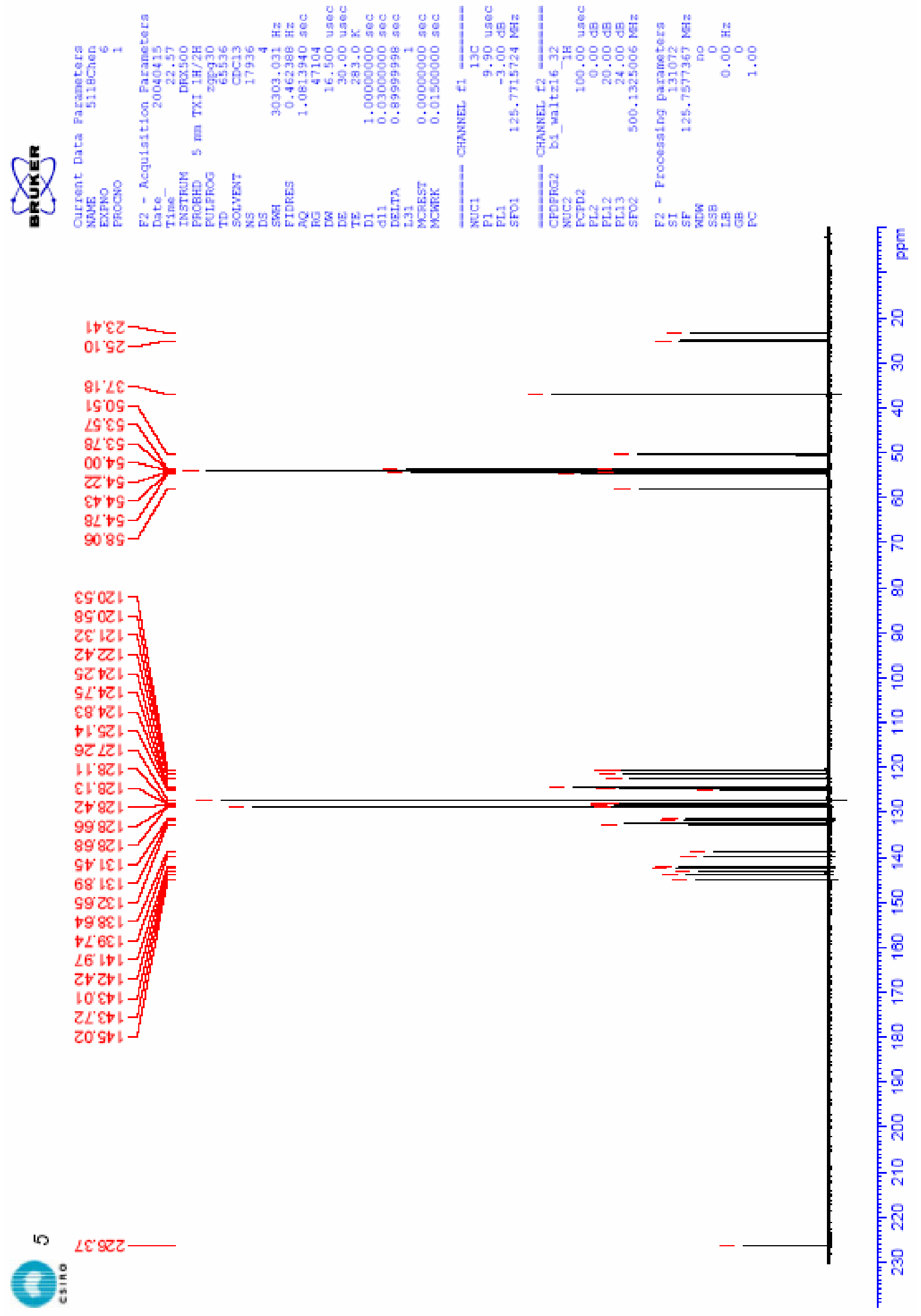



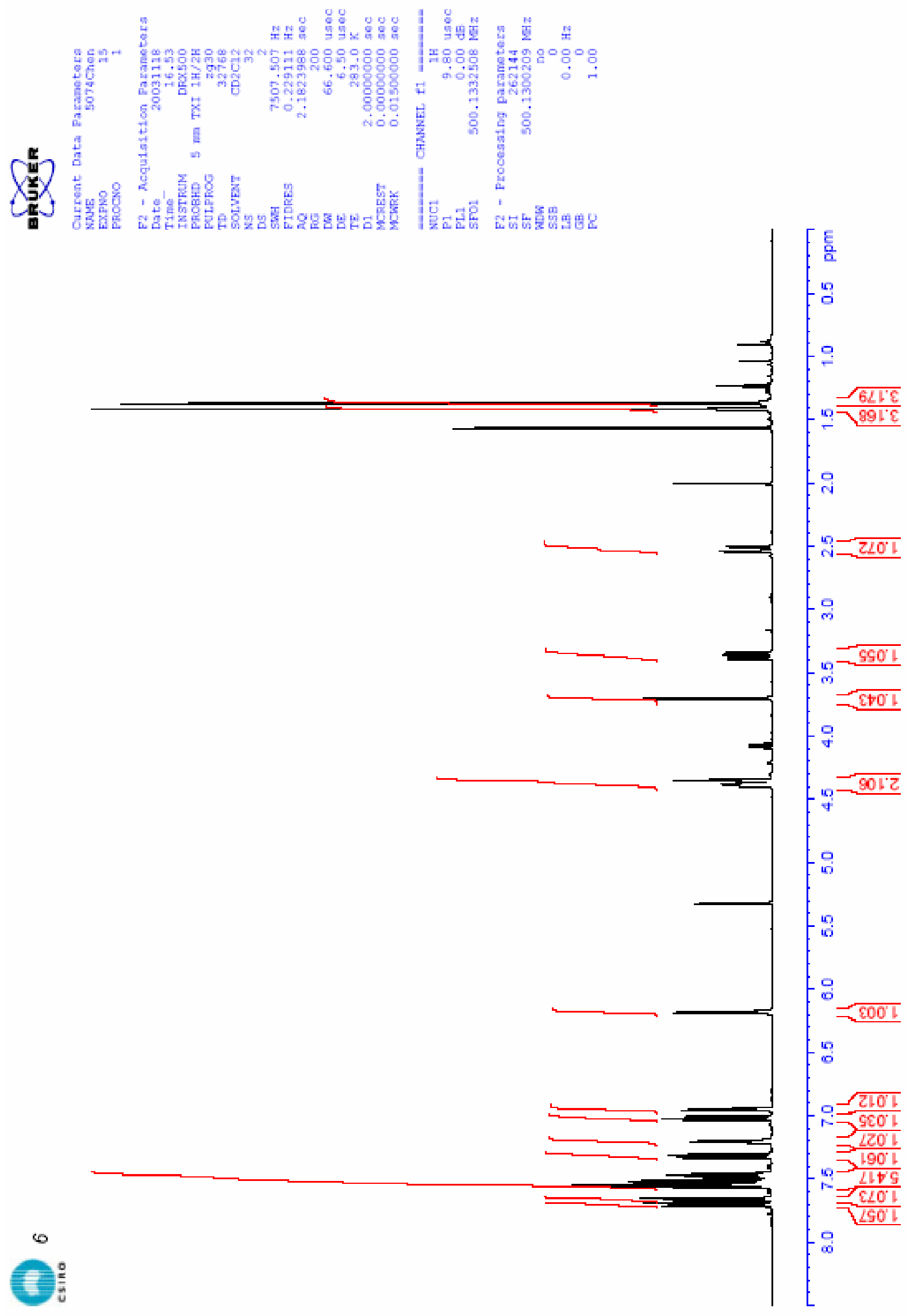

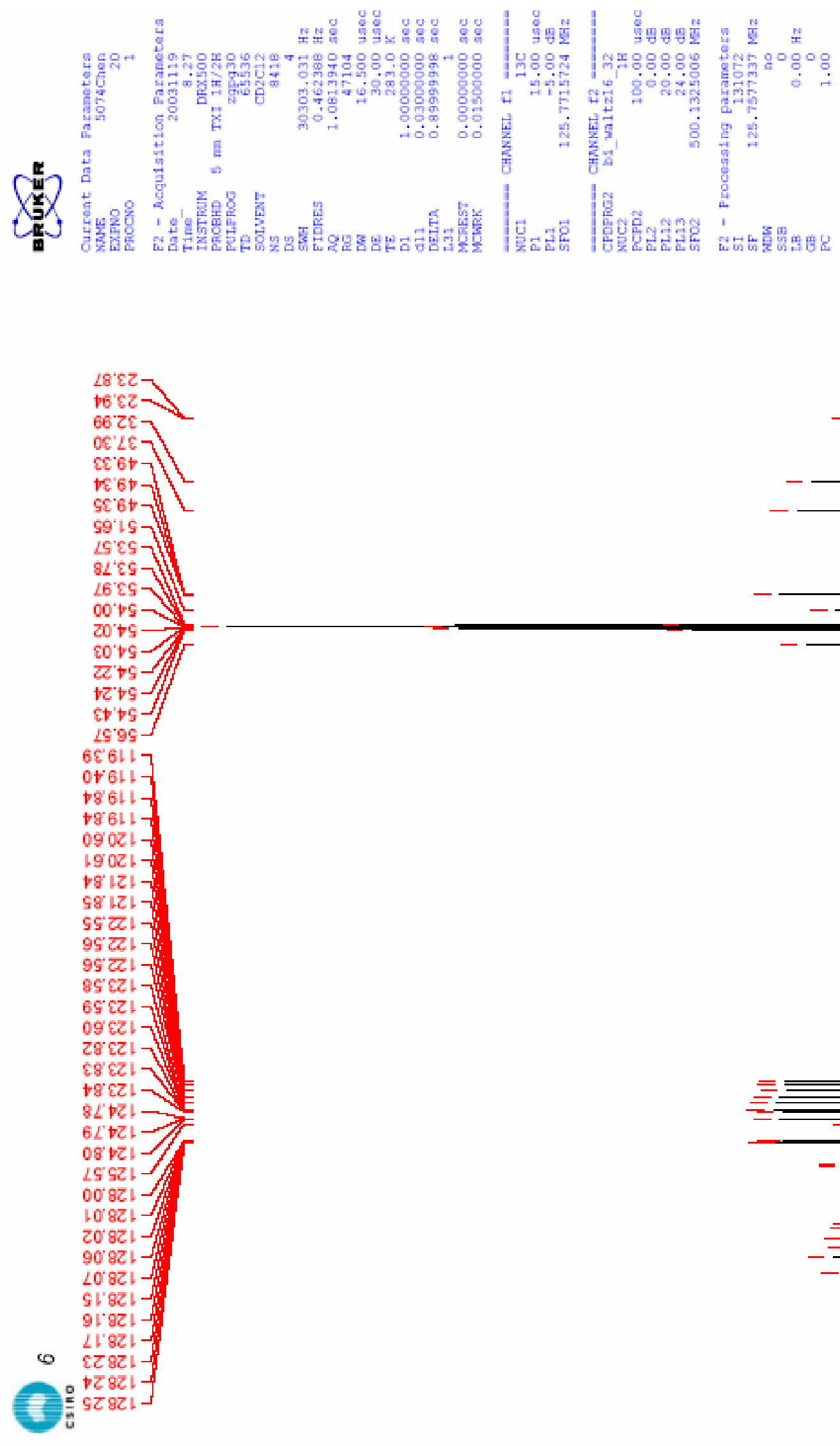

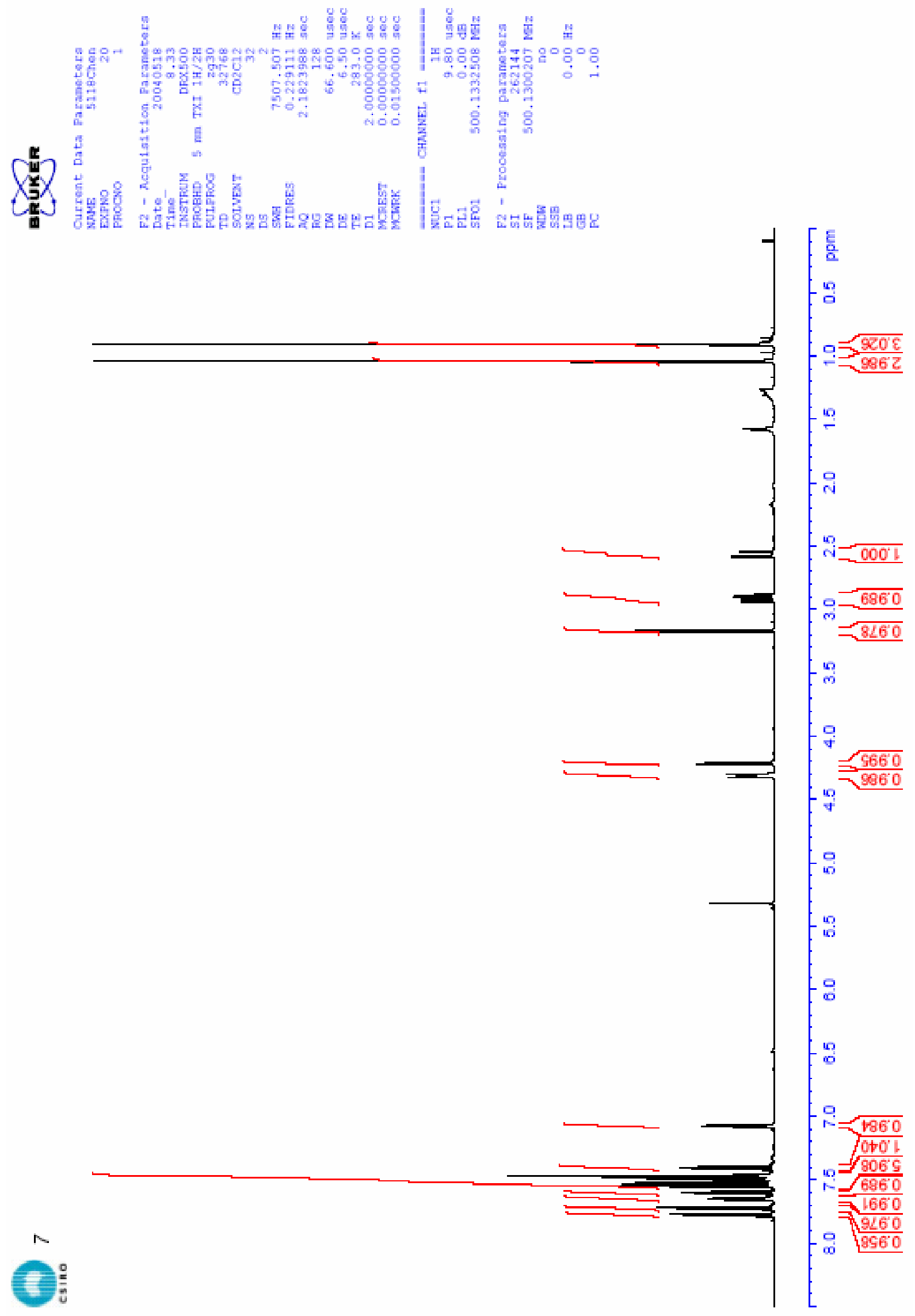

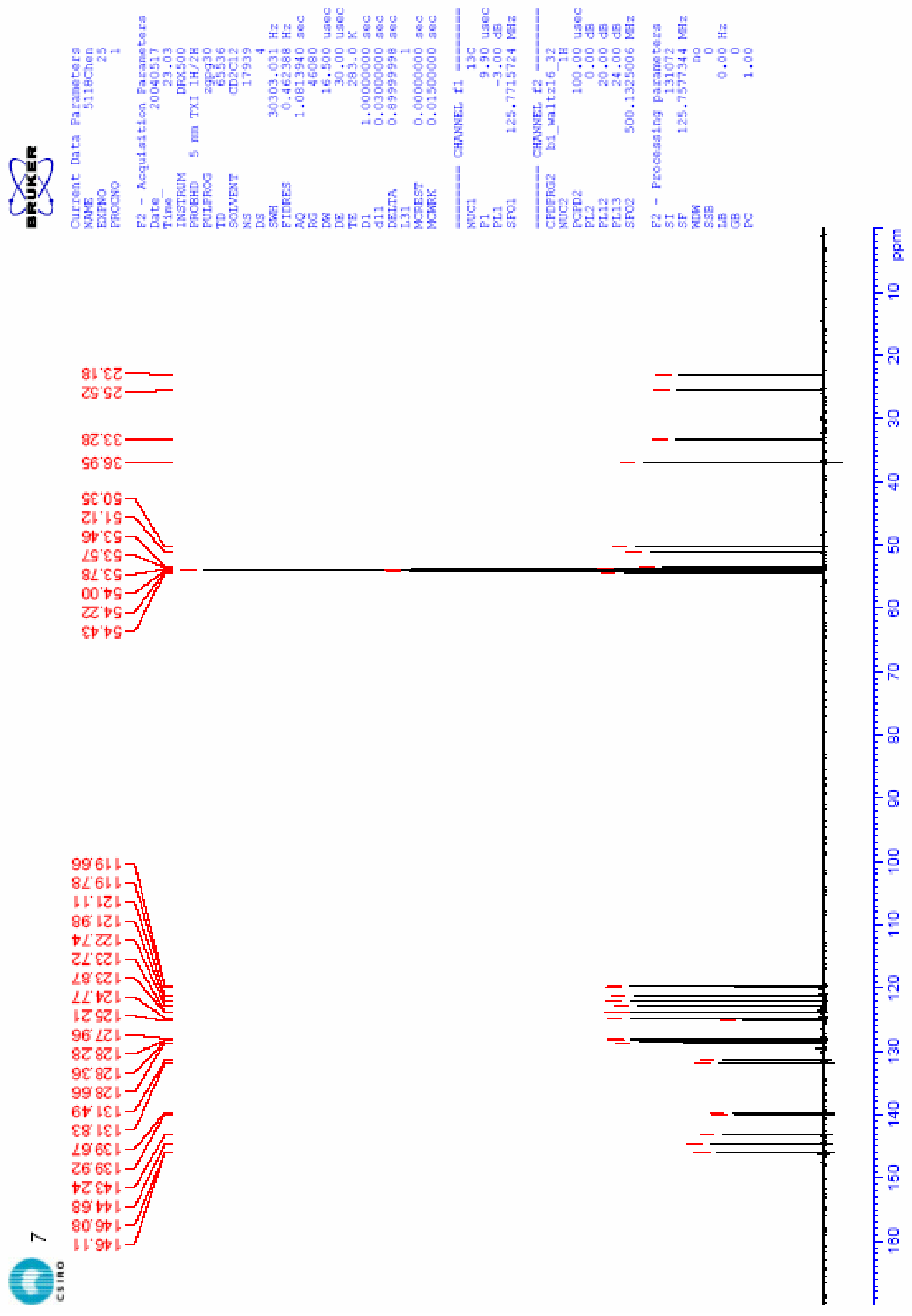

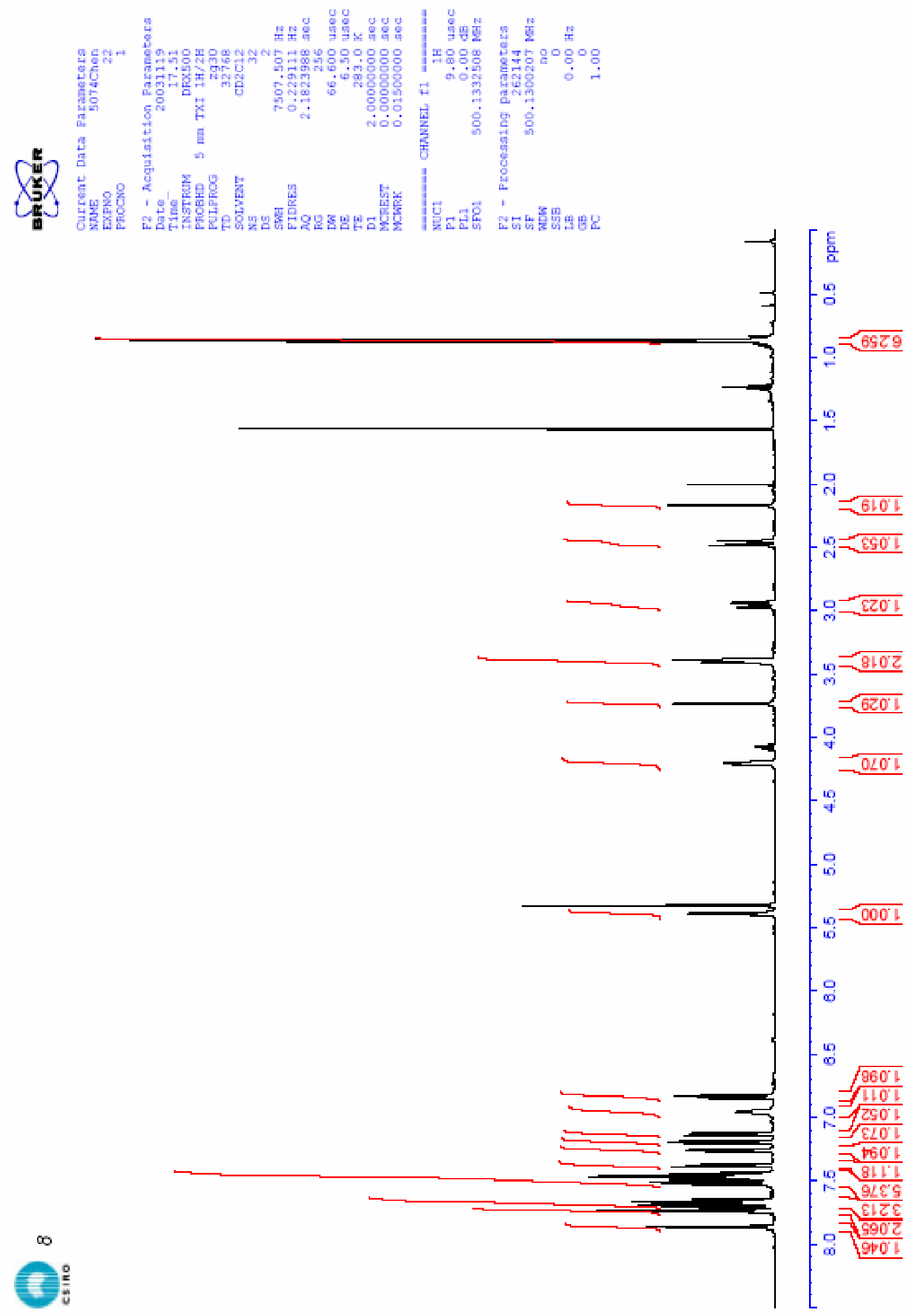

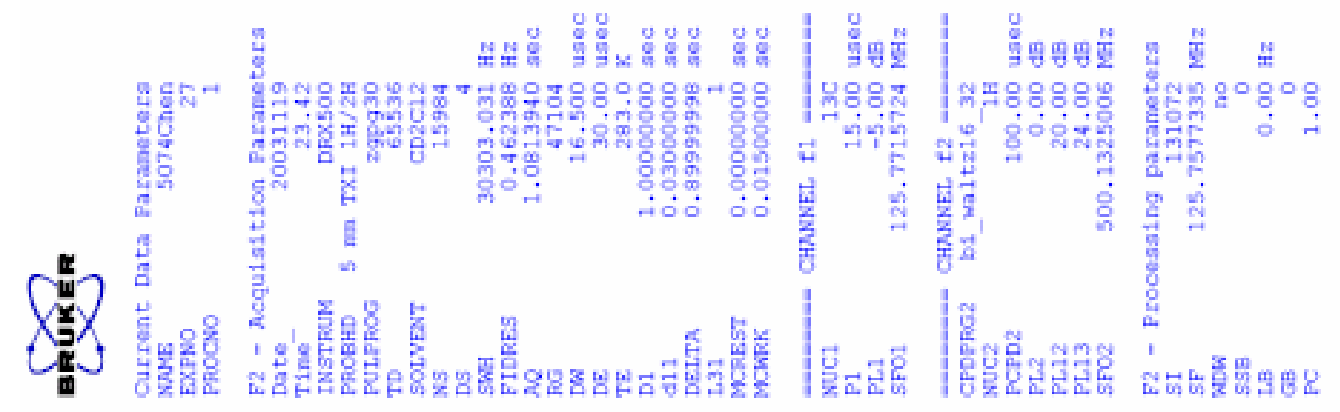

69:cz-

toes

$7998-$

8160

$9 L 05$

$0215-1$

6L'ZS

$2909-4$

gi's

oots

z'ts-

$c t+c-$

Q's
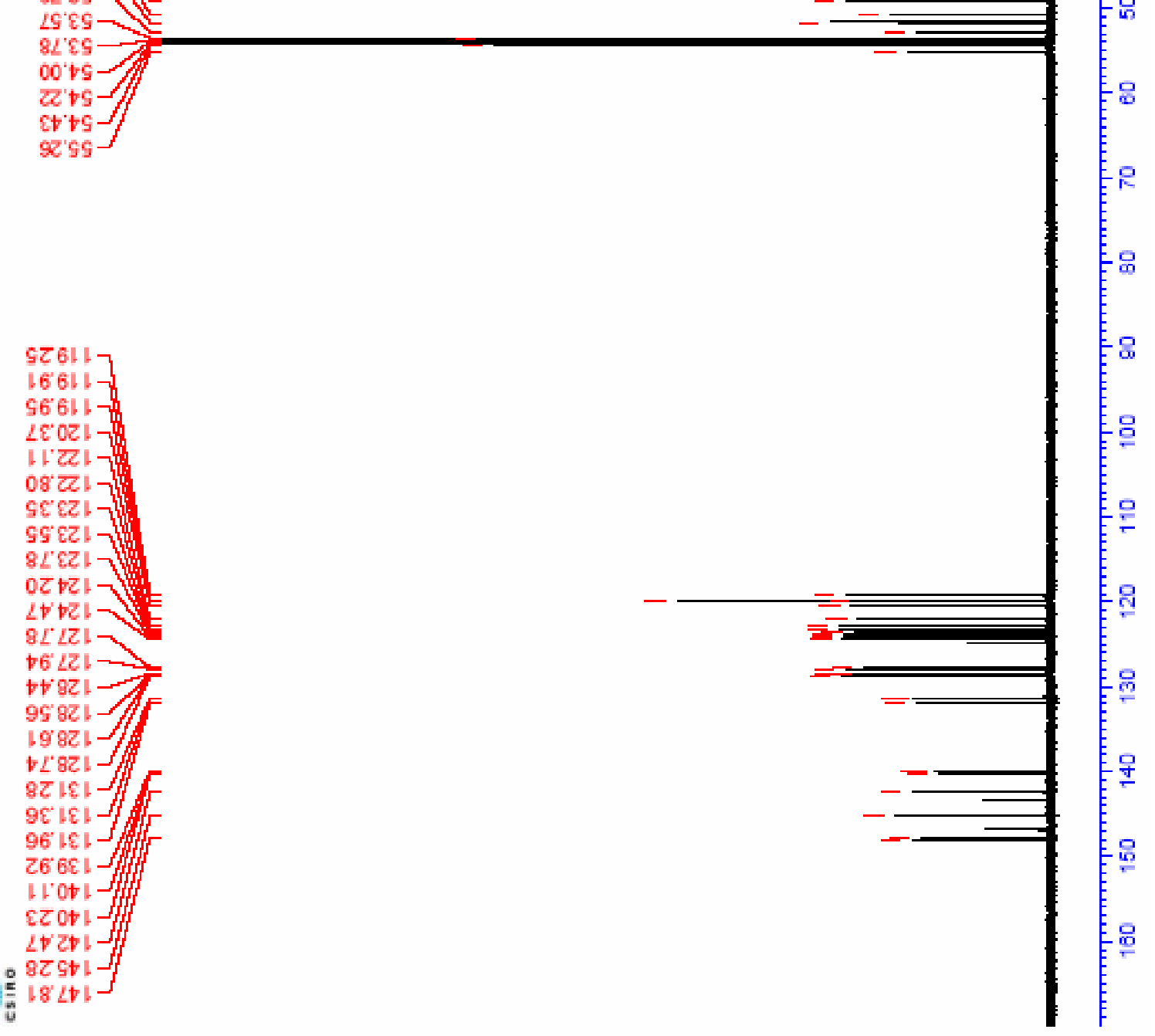

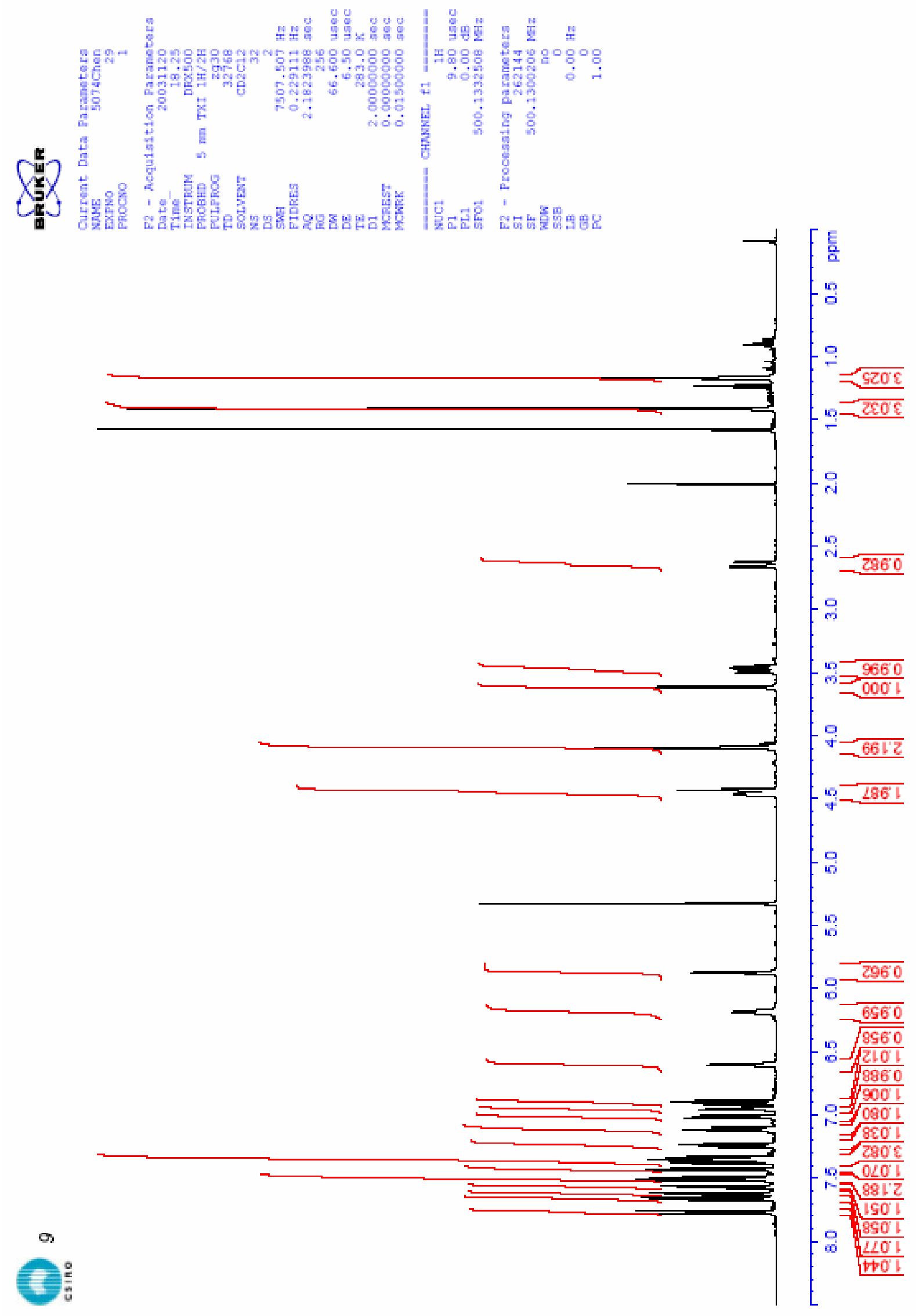

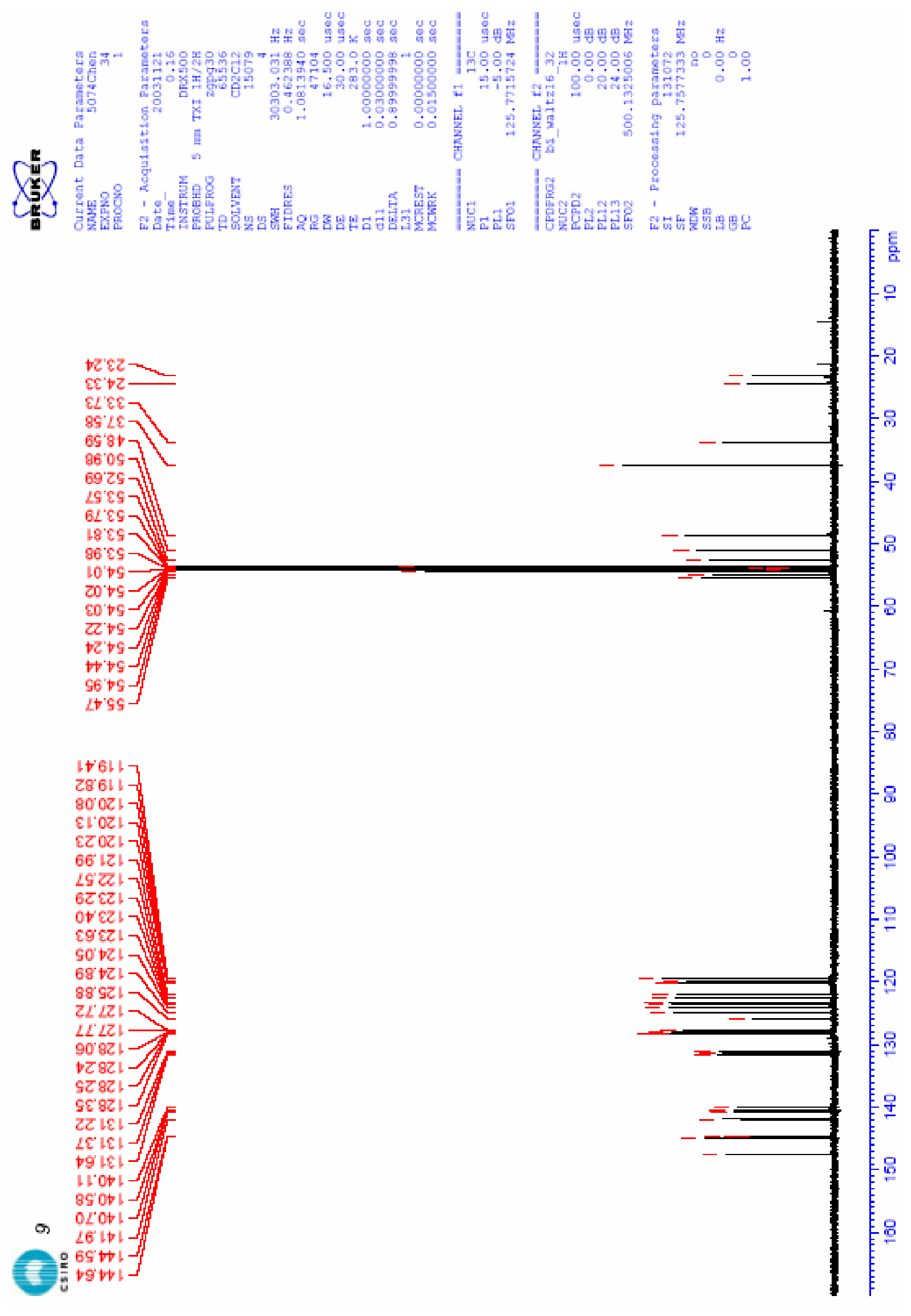

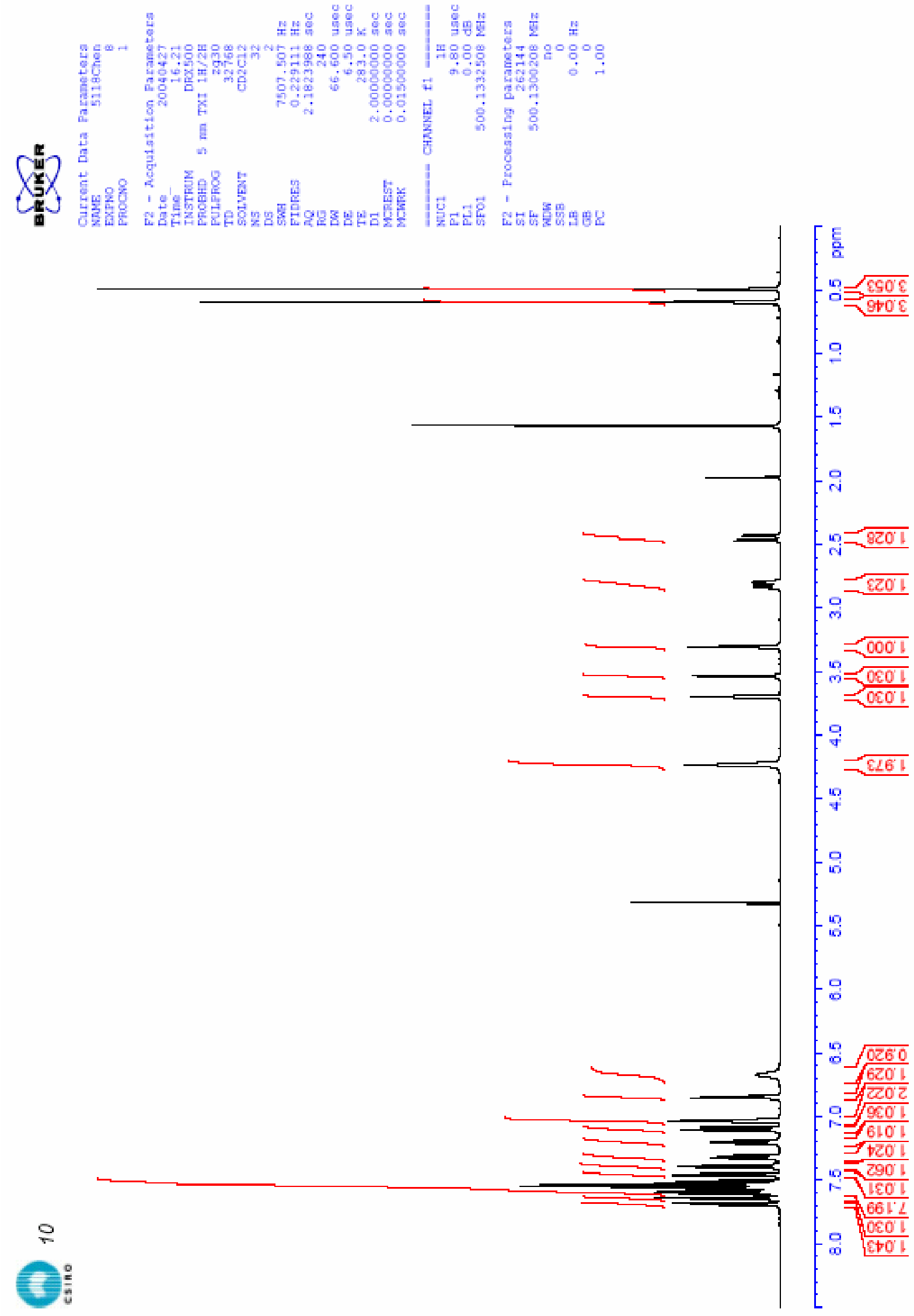

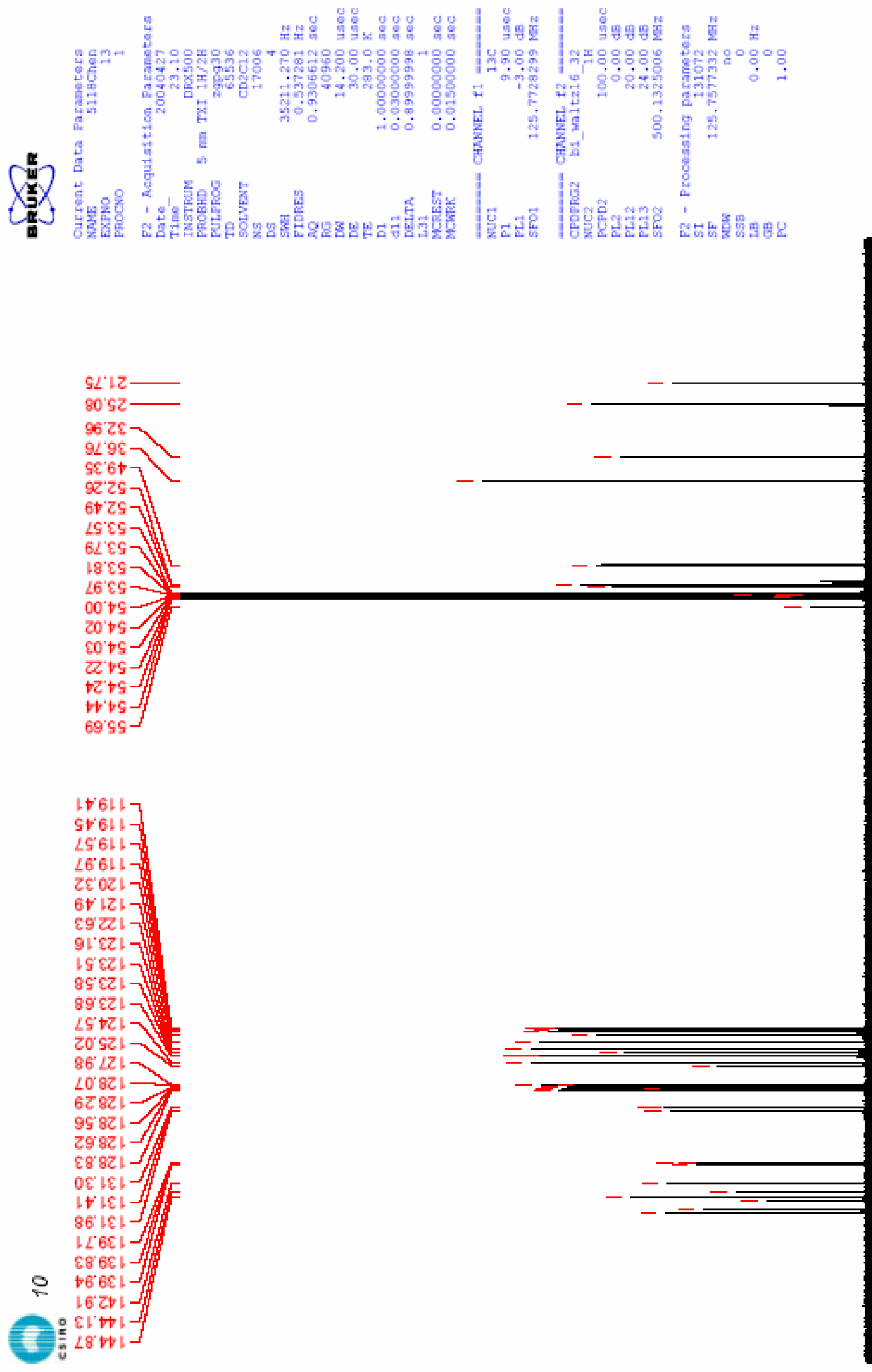

음
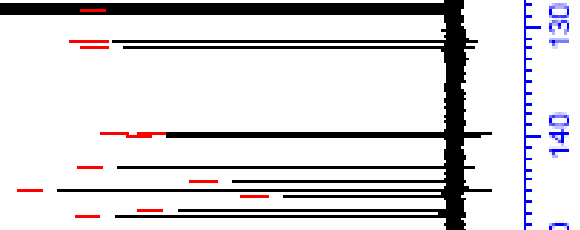

E옹 

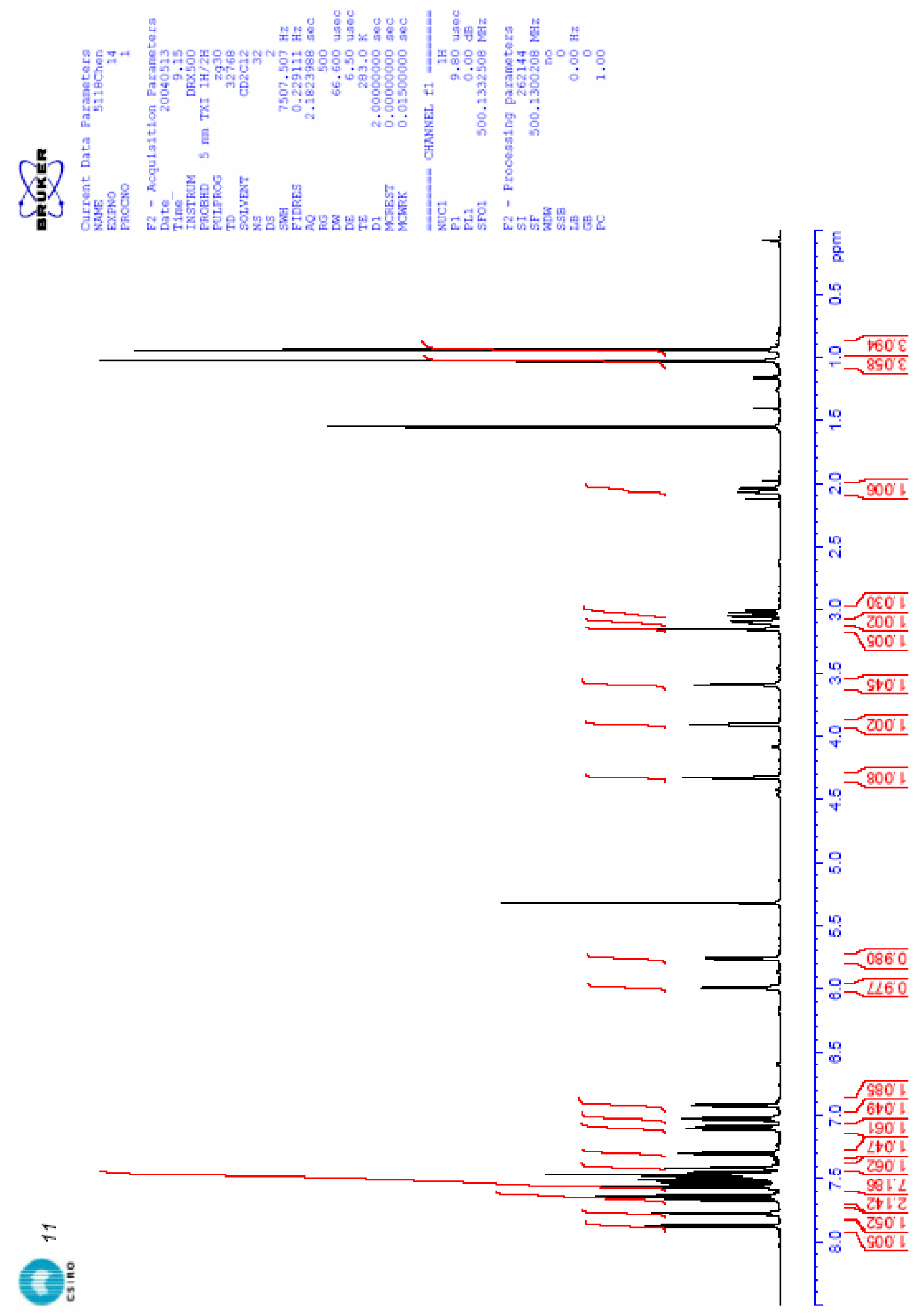


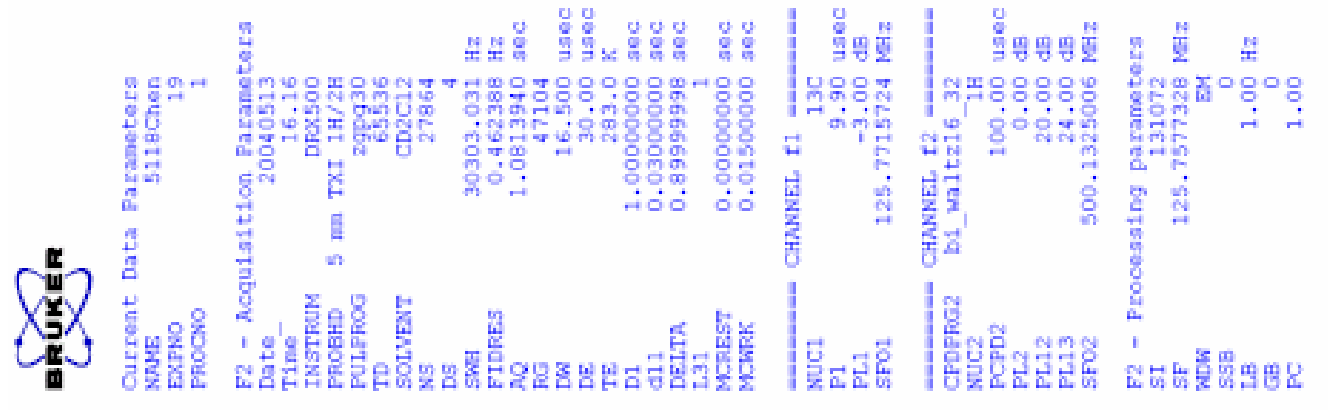

6อsZ

Le's- -

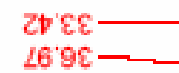

$6627>$

$1209-3$

of 1

BLCS

$06 \mathrm{se}-$

$00+s$

¿'†s

ctrs

$7999-$
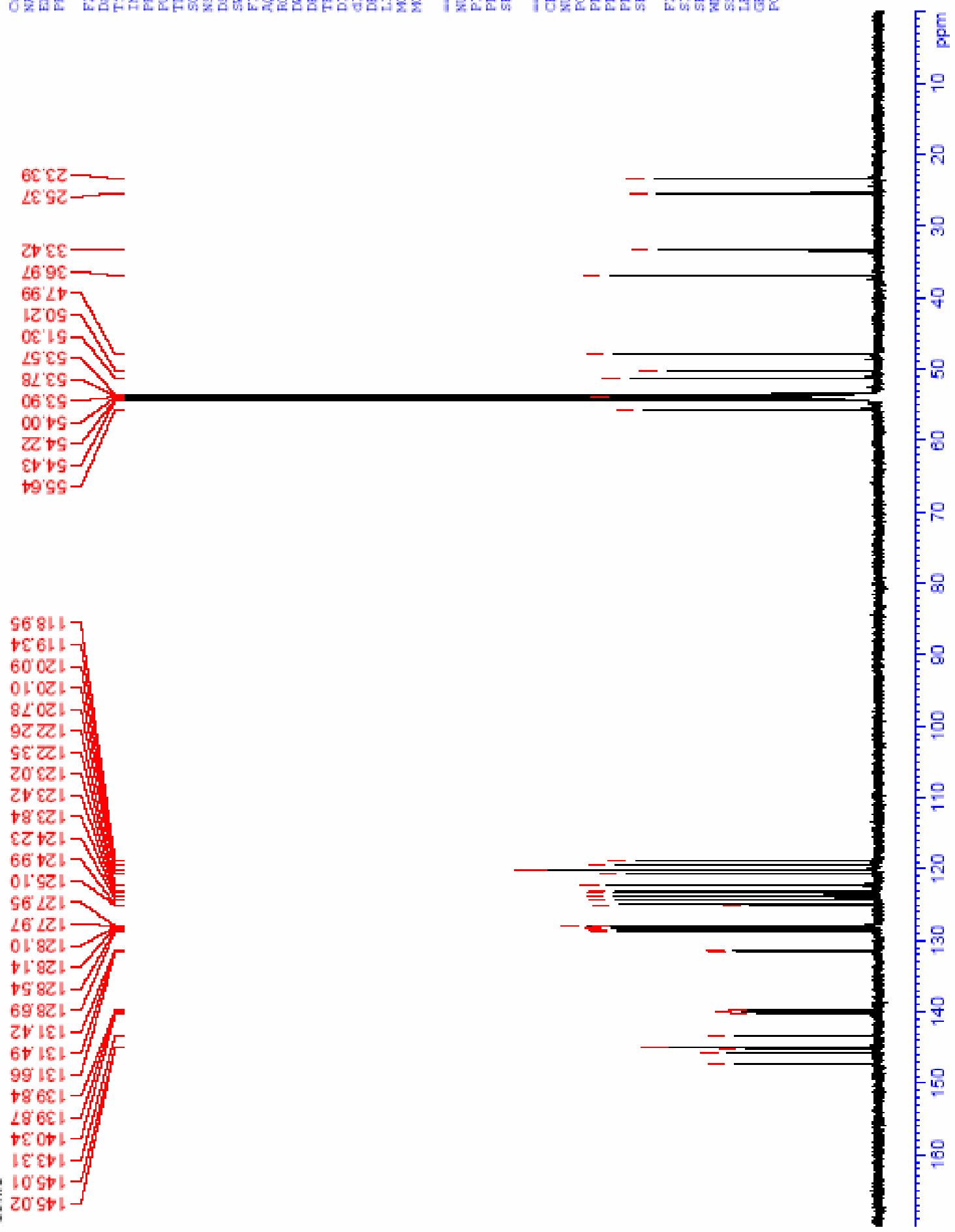